\title{
Jehovah's Witnesses and cardiac surgery: a single institution's experience
}

\author{
Sharon McCartney, ${ }^{1}$ Nicole Guinn, ${ }^{1}$ Russell Roberson, ${ }^{2}$ Bob Broomer, ${ }^{1}$ William White, ${ }^{1}$ and \\ Steven Hill ${ }^{2}$
}

BACKGROUND: Based on biblical doctrines, patients of the Jehovah's Witness faith refuse allogeneic blood transfusion. Cardiac surgery carries a high risk of blood transfusion, but has been performed in Jehovah's Witnesses for many years. The literature contains information on the outcomes of this cohort, but does not detail the perioperative care of these patients. This article describes a single institution's experience in perioperative care of Jehovah's Witnesses undergoing cardiac surgery.

STUDY DESIGN AND METHODS: A chart review of adult Jehovah's Witness patients undergoing cardiac surgery at Duke University between January 2005 and June 2012 was completed. Institutional protocols regarding preoperative erythropoietin (EPO) therapy and intraoperative isovolemic hemodilution are detailed. Patient demographics and use of various blood conservation techniques are described. Hemoglobin $(\mathrm{Hb})$ at various points throughout the perioperative management, hospital length of stay, and mortality are reviewed as indicators of outcome.

RESULTS: Forty-five Jehovah's Witness patients underwent cardiac surgery at Duke University Medical Center. Preoperative EPO increased the mean $\mathrm{Hb}$ by $1.2 \mathrm{~g} / \mathrm{dL}$ before surgery. Intraoperative normovolemic hemodilution was used in 37 patients with intraoperative mean nadir $\mathrm{Hb}$ of $10.3 \mathrm{~g} / \mathrm{dL}$. Antifibrinolytics and desmopressin were commonly used as coagulation adjuncts. Mean cardiopulmonary bypass time was 137 minutes, with mean nadir temperature of $30.5^{\circ} \mathrm{C}$. The mean length of hospital stay was 6.2 days, with mean intensive care unit stay of 1.7 days. This cohort had zero 90-day mortality in the perioperative period. CONCLUSIONS: This case series demonstrates that bloodless cardiac surgery can be performed in select patients refusing allogeneic blood transfusion.

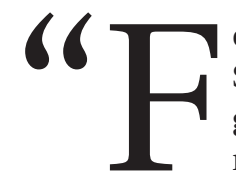
or it has seemed good to the Holy Spirit and to us to lay on you no greater burden than these requirements: that you abstain from what has been sacrificed to idols, and from blood...."1 "Because the life of every creature is its blood ... you must not eat the blood of any creature ... anyone who eats it must be cut off." ${ }^{2}$

Based on these doctrines, patients of Jehovah's Witness faith (Witnesses) refuse allogeneic blood products, viewing blood transfusion a direct violation of God's will. ${ }^{3}$ Historically, when whole blood was transfused, it was clear that Witnesses would not accept this. However, with the fractionation of blood products, the distinction has been less straightforward. In 2000 and 2004, the Watchtower Bible and Tract Society, the official Jehovah's Witness authority, declared that the primary components of blood, red blood cells (RBCs), white blood cells, platelets (PLTs), and plasma, along with whole blood, are not

ABBREVIATIONS: AS = aortic stenosis; $\mathrm{AV}=$ aortic valve; $\mathrm{BMP}=$ basic metabolic panel; $\mathrm{CABG}=$ coronary artery bypass grafting; $\mathrm{CBC}=$ Center for Blood Conservation; $\mathrm{CPB}$ = cardiopulmonary bypass; ESA(s) = erythropoietinstimulating agent(s); ICU(s) = intensive care unit(s); $\mathrm{INH}=$ intraoperative normovolemic hemodilution; $\mathrm{MV}=$ mitral valve; RAP = retrograde autologous priming; $\mathrm{TV}=$ tricuspid valve.

From the ${ }^{1}$ Department of Anesthesiology, Duke University Medical Center, Durham, North Carolina; and the ${ }^{2}$ Department of Anesthesiology, University of Texas-Southwestern, Dallas, Texas.

Address correspondence to: Nicole Guinn, Department of Anesthesiology, Duke University Medical Center, DUMC 3094, Durham, NC 27710; e-mail: Nicole.Guinn@dm.duke.edu.

Received for publication October 15, 2013; revision received March 14, 2014, and accepted March 14, 2014.

doi: $10.1111 /$ trf. 12696

(C) 2014 AABB

TRANSFUSION 2014;54:2745-2752. 
acceptable for transfusion by Witnesses., ${ }^{3,4}$ They deemed the fractions of blood, such as immunoglobulins, albumin, and fractionated clotting factors, as left to the individual's personal choice and is a matter of conscience for each individual to decide. As such, there is varying acceptance of these components of blood among Witnesses.

This unique population presents new approaches to management in the perioperative arena. Cardiac surgery has been performed in Witnesses without blood product transfusion for more than 50 years. There have been multiple reports showing low morbidity and mortality in this population, as well as equivalent or improved outcomes. ${ }^{5-7}$ Advances in pharmacologic support, including introduction of erythropoietin (EPO)-stimulating agents (ESAs) to treat preoperative anemia, and surgical technique have led to these improved outcomes, despite a patient population with growing comorbidities.,

Blood transfusion during or after cardiac surgery is associated with increased morbidity and mortality, ${ }^{8,9}$ and guidelines to conserve blood products in non-Witness patients have shown improved outcomes and reduced costs. ${ }^{9,10}$ Although the literature has demonstrated that bloodless cardiac surgery is possible and potentially beneficial to patients, it requires preoperative optimization and a multidisciplinary team. There are few published studies that provide details of an institution's optimization process, as well as detailed perioperative management of Witnesses undergoing cardiac surgery. This article discusses the perioperative management of 45 Witnesses undergoing cardiac surgery at a single institution between January 2005 and June 2012.

\section{MATERIALS AND METHODS}

With institutional review board approval, a chart review of all Witnesses undergoing cardiac surgery at Duke University Medical Center between January 2005 and June 2012 was completed. All Witnesses undergoing cardiac surgery were identified and screened before surgery by Duke's Center for Blood Conservation (CBC). The CBC consists of a medical director, a program manager, and a blood conservation specialist with intimate knowledge of the Jehovah's Witness faith. The CBC consults with all patients refusing blood products who are admitted to the hospital or considered for surgery. The CBC confirms the patient's wishes regarding blood product refusal and elicits which, if any, products or procedures the patient will accept. The patient signs a consent detailing the refusal of blood products. The $\mathrm{CBC}$ acts as an advocate for patients, in addition to serving as a source of information regarding products or procedures that they may be unfamiliar with, so that patients can make informed decisions regarding refusal of such items. The CBC makes recommendations for the medical and surgical teams regarding preparation for invasive procedures and assists in selecting the perioperative team, including perfusion services and the anesthesiologist.

Patients' electronic medical records were examined to identify demographic characteristics such as age, race, and sex, in addition to their preoperative height, weight, and body mass index. Their preoperative hemoglobin $\mathrm{Hb}$, defined as the $\mathrm{Hb}$ reported when the patient was referred to the $\mathrm{CBC}$, was recorded; in addition, $\mathrm{Hb}$ was recorded on the day of surgery, intraoperative nadir, at the end of surgery, Postoperative Day 1, and the day of discharge. The electronic records were also examined to evaluate which patients received support with ESAs, cryoprecipitate, plasma protein fraction, DDAVP, and antifibrinolytics. The volume of autologous blood removed, but kept in continuous circuit with the patient during intraoperative normovolemic hemodilution (INH), was recorded, in addition to the $\mathrm{Hb}$ after INH. The type of surgery, total cardiopulmonary bypass (CPB) time, and degree of hypothermia were recorded for each patient. If reinitiation of $\mathrm{CPB}$ was necessary, this was included in the total CPB time. The patient's length of hospital stay, defined as the surgery date to the discharge date, was recorded.

For a patient to be considered for preoperative ESAs, the institution's CBC protocol was followed. Inclusion criteria are age more than 18 years old, signed refusal of blood products, iron saturation of at least $20 \%$, and ferritin level of at least $90 \mathrm{ng} / \mathrm{mL}$. Patients are excluded from preoperative ESAs if they have comorbidities including iron deficiency without iron store replacement, myelodysplasia, myeloid cancers, pure RBC aplasia, uncontrolled hypertension, history of thrombosis, or a history of malignancy with known EPO receptors. A protocol for ESA administration dosage and timing has been established and is shown in Table 1. All patients receive oral (time permitting and if tolerated by the patient) or intravenous (IV) iron infusion concomitant with ESA treatment. Reticulocyte counts are obtained on initial preoperative consultation in addition to iron studies. If the patient's $\mathrm{Hb}$ does not respond to ESAs, the reticulocyte count is repeated, with iron studies. $\mathrm{Hb}$ is used as the primary measure to evaluate the efficacy of ESAs.

Witnesses undergoing cardiac surgery at Duke University undergo INH unless they are undergoing off-pump coronary artery bypass grafting (CABG). Additionally, INH may not be used in critical aortic stenosis (AS) or severe left main (or equivalent) disease, due to the possibility that a decrease in preload can be life-threatening; however, this decision is individualized based on the severity of the vavular or coronary stenosis, the patient's starting $\mathrm{Hb}$, and the patient's size (blood volume). INH is initiated after induction of anesthesia and placement of large-bore central venous access. Other requirements 
TABLE 1. Protocol for administration of preoperative EPO in Jehovah's Witness patients undergoing cardiac surgery ${ }^{*}$

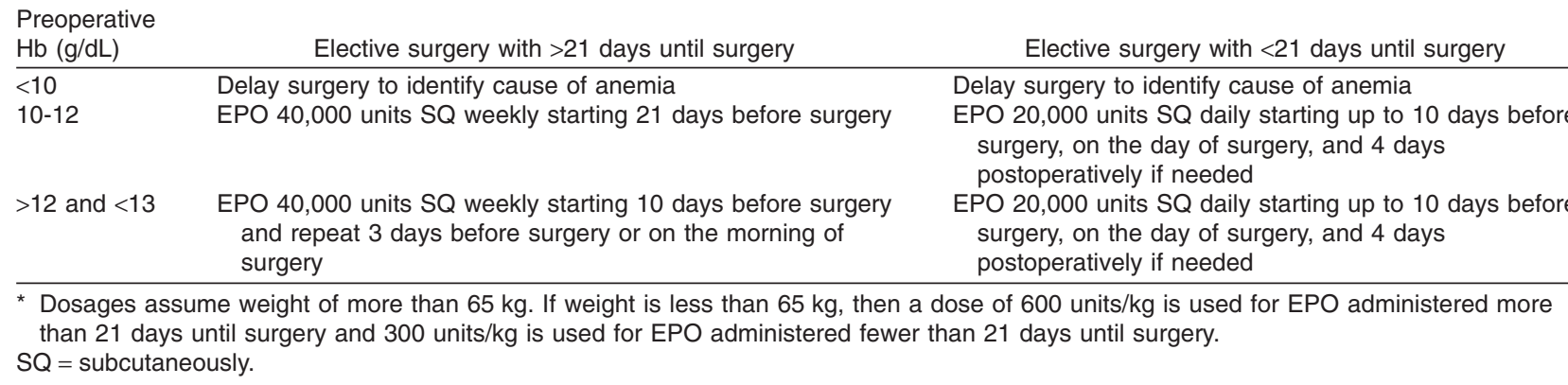

include an arterial catheter to closely monitor hemodynamics and a large-bore peripheral IV for fluid and medication infusion. One provider is dedicated to observing the autologous harvest. Autologous harvest is achieved by connecting tubing from the central venous line to four collection bags that contain citrate for anticoagulation. The secondary lumens of the central venous line are not used during autologous harvest. Autologous harvest volume is calculated based on the most recent $\mathrm{Hb}$, which is taken upon arrival to the operating room. A weightbased calculation is used. First, the weight is calculated by using the ideal body weight (IBW):

$$
\text { Weight }=\mathrm{IBW}+0.33(\text { actual weight }-\mathrm{IBW}) \text {. }
$$

The target volume to be harvested is then calculated:

$$
\text { Harvest volume }=\frac{\text { weight } \times 70(\mathrm{Hb}-\text { target } \mathrm{Hb})}{\mathrm{Hb}}
$$

[Correction added after online publication 09-May-2014: the Harvest volume formula has been updated.]

The target $\mathrm{Hb}$ is typically $9 \mathrm{~g} / \mathrm{dL}$, but a decrease in $\mathrm{Hb}$ of more than $50 \%$ from baseline is avoided. The autologous harvest blood is directed sequentially into three to four citrated bags, with target volume of 400 to $500 \mathrm{~mL}$ per bag. A scale is used to determine the amount of blood obtained per bag. Hemodynamics are closely monitored during this time, and hypotension is treated with IV phenylephrine. No IV fluid is given following the first bag of collected autologous blood, as this volume has been replaced with approximately $750 \mathrm{~mL}$ of crystalloid typically given during induction of anesthesia. No IV fluids are given during collection of each bag of blood; however, after the second and third bags of harvested blood, colloid fluid is given in a 1:1 mL fashion to replace the volume of harvested blood. If a fourth unit of blood is harvested, 1 liter of crystalloid is administered afterward. If the patient experiences hypotension that is unresponsive to vasopressors during harvest, INH is paused. INH is completed before heparinization. The harvested blood is kept on a rocker at room temperature during the operative procedure. The blood is typically returned to the patient after separation from CPB and reversal of heparin, but may be returned while still on $\mathrm{CPB}$ to obtain goal $\mathrm{Hb}$ of more than $7 \mathrm{~g} / \mathrm{dL}$. Autologous blood is given back to the patient in the reverse order that it was withdrawn and remains unwarmed. Reinfusion of autologous blood must be completed within 8 hours of harvest.

Retrograde autologous priming (RAP) of the CPB machine is performed in all patients, given hemodynamic tolerance. Additionally, cell saver is used in all cardiac surgeries. As with the harvest blood from INH, this blood is kept in continuous circuit with the patient, according to patient's religious preference and therefore must be primed and attached to an IV line at the beginning of the procedure. Patients are informed, however, regarding the possible momentary discontinuation of the continuous circuit in the event of clot or air in the machine. Cell saver product is devoid of PLTs and plasma proteins and could contribute to dilutional coagulopathy if used extensively. Therefore, cell saver suction is used during opening and closing when the patient is not heparinized. Whole blood is suctioned to the cardiotomy reservoir for return to the patient via the CPB pump during full anticoagulation in an attempt to limit cell saver product returned to 2 units for each case. Cell saver product and concentrated residual whole blood from the $\mathrm{CPB}$ machine are returned to the patient before initiation of autologous harvest transfusion. The last $50 \mathrm{mg}$ of protamine is administered after infusion of the heparinized whole blood from the bypass circuit. Anticoagulation is fully reversed before autologous harvest transfusion, to avoid loss of RBCs from inadequate hemostasis. A thromboelastography and fibrinogen level are obtained at the end of bypass to assess coagulation status. The patient remains in the operating room until the surgeon decides that adequate hemostasis has been achieved based on observation of a dry surgical field, with the use of tissue coagulants, if necessary. If there is any concern for inadequate hemostasis due to high chest tube output ( $>400 \mathrm{~mL}$ in the first hour) in the intensive care unit (ICU), the patient is urgently brought 
back to the operating room for exploration. Salvage therapy with reinfusion devices for chest tube output are not used.

All patients recover postoperatively in a dedicated cardiothoracic surgery ICU, supervised by cardiothoracic anesthesiologists and cardiothoracic surgeons. Phlebotomy is minimized postoperatively by using zero-waste blood drawing sets and pediatric size laboratory tubes, which require less than $1 \mathrm{~mL}$ of blood per tube. Additionally, intensivists and staff attempt to minimize phlebotomy to that which is essential for patient management, including a thromboelastography, fibrinogen, and basic metabolic panel (BMP) obtained on admission to the ICU. Arterial blood gases are used to monitor both $\mathrm{Hb}$ and electrolytes while in the ICU. Basic coagulations studies (prothrombin time, partial thromboplastin time, and international normalized ratio) are not routinely monitored during the hospitalization, since the patient refuses replacement of products for correction of these laboratory abnormalities. A BMP is obtained on Postoperative Day 1 to assess renal function. After discharge from the ICU, a complete blood count and BMP are typically obtained every other day to monitor $\mathrm{Hb}$, electrolytes, and renal function. ESAs can be used postoperatively at the discretion of the care team if the patient has anemia, with the dosing algorithm similar to that used preoperatively.

\section{Statistical analysis}

All data were processed and analyzed with computer software (Excel, Version 14.3.4, Microsoft, Inc., Redmond, WA). Data are given as mean \pm standard deviation (SD) or median (range) as appropriate.

\section{RESULTS}

Forty-five Witnesses had cardiac surgery at Duke University between January 2005 and June 2012 and were included in the study. One patient was denied cardiac surgery due to a new diagnosis of metastatic renal cell carcinoma. All patients accepted fractions and procedures; therefore, no patients were excluded from surgery due to their refusal preferences. Preoperative patient characteristics and surgical procedure are described in Table 2. Twenty-three patients had CABG as a single operation. Eighteen patients had valvuloplasty or valve replacement of the mitral (MV), tricuspid (TV), or aortic valve (AV), including one patient who had both MV and AV surgery, one who had both MV and TV surgery, one patient who had AV replacement in addition to endovascular abdominal aortic aneurysm repair, and one patient who underwent TV repair with removal of right ventricular tumor. Four patients had combined CABG plus valve surgery of either the AV or the MV.

\begin{tabular}{|lc|}
\hline \multicolumn{2}{|c|}{$\begin{array}{c}\text { TABLE 2. Demographics of } 45 \text { Jehovah's } \\
\text { Witness patients undergoing cardiac surgery* }\end{array}$} \\
\hline Demographic & JW patients $(n=45)$ \\
\hline Age (years) & $63.4( \pm 12.4) ; 66(21-83)$ \\
BMI & $30.6( \pm 7.3) ; 30.6(18.90-51.4)$ \\
Height (cm) & $169.6( \pm 10.4) ; 171(147.3-188)$ \\
Female & $22(48.90)$ \\
ASA status & $1(2.22)$ \\
2 & $12(26.67)$ \\
3 & $32(71.11)$ \\
4 & $29(64.44)$ \\
Race & $14(31.11)$ \\
Caucasian & $2(4.44)$ \\
African American & $23(51.1)$ \\
Hispanic & $4(8.9)$ \\
Surgery type & $18(40.0)$ \\
CABG & \\
CABG plus valve & \\
Valve only & \\
* Data are reported as mean $( \pm S D) ;$ median (range) or group \\
number (group \%). \\
ASA = American Society of Anesthesiologists; BMI = body mass \\
index.
\end{tabular}

\section{Preoperative management}

Preoperative optimization of the patient's $\mathrm{Hb}$ was managed by the institution's CBC, according to the ESA protocol described previously. Forty of the patients received preoperative ESAs. Mean $( \pm S D)$ total dose of EPO was 109,268 $( \pm 45,124)$ units (range, 40,000-220,000 units). Hb values increased from a mean $( \pm S D)$ of $12.8( \pm 1.4) \mathrm{g} / \mathrm{dL}$ (range, $9.3-16.1 \mathrm{~g} / \mathrm{dL}$ ) to $14.0( \pm 1.5) \mathrm{g} / \mathrm{dL}$ (range, 11.1$16.6 \mathrm{~g} / \mathrm{dL}$ ) in the patients who received preoperative ESAs. All patients were started on iron supplementation (325 mg of ferrous sulfate, three times daily) upon consultation with the CBC. Twelve patients received IV iron supplementation, with eight patients having received iron sucrose, one iron gluconate, and one iron sucrose after intolerance to iron dextran, and two patients' formulation were not recorded. Given institutional formulations at the time of this study, the CBC recommended dosing of iron sucrose $200 \mathrm{mg}$ given over 2 to 3 hours, unless the patient was on hemodialysis, in which case dosing was determined by the patient's nephrologist. The reasons for use of IV iron in these 12 patients included impending urgent cardiac surgery and intolerance to oral iron supplementation.

Use of preoperative anticoagulants were reviewed and discontinued by the $\mathrm{CBC}$ in conjunction with the surgical team. Five patients were taking clopidogrel preoperatively, with discontinuation at least 7 days before surgery. Five patients were taking warfarin; this was discontinued and the international normalized ratio was normalized $(<1.2)$ before surgery. One patient was taking fondaparinux for history of deep venous thrombosis (DVT), which was stopped 5 days before surgery. One patient was taking aspirin with extended-release dipyridamole; however, it is unclear when this was 


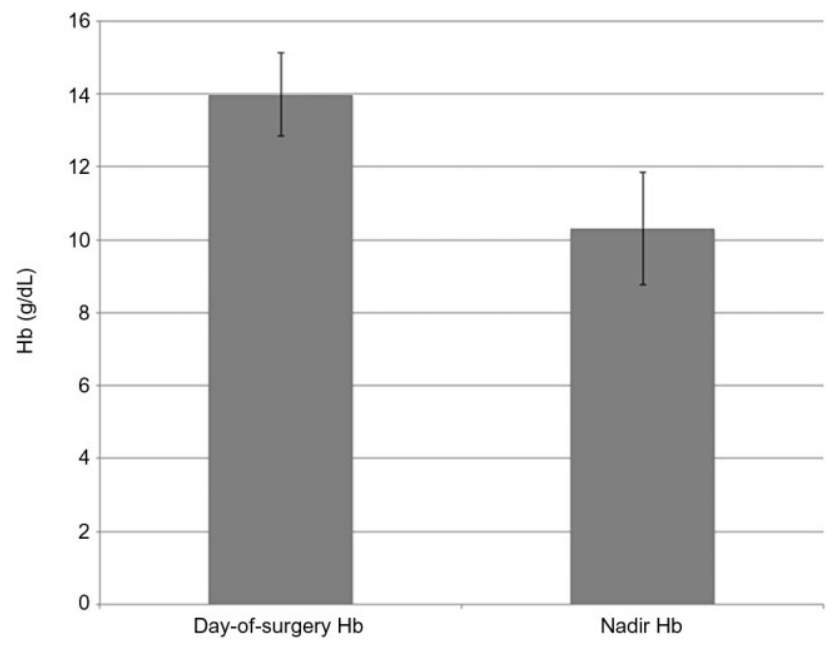

Fig. 1. Maximum change in intraoperative $\mathrm{Hb}$ during cardiac surgery.

stopped preoperatively. All patients deemed high risk for thrombosis by the surgical team, such as those with increasing coronary ischemia or history of recent deep venous thromboses, were bridged with IV heparin. Aspirin (81 or $325 \mathrm{mg}$ ) was continued in all patients.

\section{Intraoperative management}

Thirty-seven of the patients underwent INH before initiation of CPB. Two patients who did not undergo INH were receiving $A V$ replacements for critical AS, five patients had off-pump CABG, and one had on-pump CABG. The one patient who did not receive INH who underwent on-pump CABG had severe left main disease, and this was likely the reason INH was not used. Autologous harvest volumes ranged from 800 to $2000 \mathrm{~mL}$ based on the patient's weight and preoperative $\mathrm{Hb}$, with a mean $\pm \mathrm{SD}$ volume of $1434 \pm 359.8 \mathrm{~mL}$. Posthemodilution $\mathrm{Hb}$ ranged from 6.8 to $12.8 \mathrm{~g} / \mathrm{dL}$. Mean $( \pm \mathrm{SD}$ ) day of surgery Hb was $14.0( \pm 1.1) \mathrm{g} / \mathrm{dL}$ (range, 11.1-16.6 g/dL), compared to mean $( \pm \mathrm{SD})$ intraoperative nadir $\mathrm{Hb}$ of $10.3( \pm 2.2) \mathrm{g} / \mathrm{dL}$ (range, 6.8-13.3 g/dL), with a mean $( \pm \mathrm{SD})$ decrease of 3.68 $( \pm 1.4) \mathrm{g} / \mathrm{dL}$ (range, $0.8-7.2 \mathrm{~g} / \mathrm{dL}$ ) or a $26 \%$ decrease in $\mathrm{Hb}$ (mean \pm SD, $0.26 \pm 0.097$; range, 0.057-0.49; Fig. 1). Three patients had low intraoperative $\mathrm{Hb}(<8 \mathrm{~g} / \mathrm{dL})$, near the level of transfusion triggers for many clinicians. Before its discontinuation in 2007, aprotinin was the most commonly used antifibrinolytic. Thirteen patients received therapy with aprotinin, 28 patients received aminocaproic acid, and four patients received no antifibrinolytics during surgery. Three of the four patients who did not receive antifibrinolytics underwent off-pump CABG and the fourth patient underwent emergent on-pump CABG. One patient received both cryoprecipitate and cryopoor plasma. Eighteen patients received desmopressin to enhance PLT function after CPB. Eight of these patients had moderate to severe AS and one patient had end-stage renal failure. The other nine patients may have received desmopressin for coagulopathy and presumed PLT dysfunction as perceived by the surgical team.

Total CPB times ranged from 43 to 301 minutes, with a mean $( \pm S D)$ of $137( \pm 4.7)$ minutes. Five patients had off-pump CABG. All patients who were placed on CPB were cooled. The mean $( \pm \mathrm{SD})$ nadir temperature was 30.5 $( \pm 2.5)^{\circ} \mathrm{C}$ (range, $26-35^{\circ} \mathrm{C}$ ). Subgroup analysis showed that patients undergoing valve surgery, including $\mathrm{CABG}$ plus valve, had a mean $( \pm \mathrm{SD})$ nadir temperature of $29.4( \pm 2.1)^{\circ} \mathrm{C}$ (range, $26-34^{\circ} \mathrm{C}$ ), while patients undergoing $\mathrm{CABG}$ had a mean $( \pm \mathrm{SD})$ nadir temperature of $31.6( \pm 2.4)^{\circ} \mathrm{C}$ (range, $\left.26.8-35^{\circ} \mathrm{C}\right)$.

\section{Postoperative management}

One patient was taken back to the operating room within the first 14 hours postoperatively for reexploration. Nine patients received postoperative ESAs for their anemia. The mean $( \pm$ SD) ESA dose used postoperatively was 37,167 $( \pm 20,273)$ units (range, $4500-80,000$ units). In the patients who received postoperative ESAs, the mean $( \pm \mathrm{SD}) \mathrm{Hb}$ at the end of surgery was $10.6( \pm 1.3) \mathrm{g} / \mathrm{dL}$ (range, 8.7-12.3 g/ $\mathrm{dL}$ ) and discharge $\mathrm{Hb}$ was $9.9( \pm 1.8) \mathrm{g} / \mathrm{dL}$ (range, 7.1$12.9 \mathrm{~g} / \mathrm{dL}$ ). Two patients were discharged with significant anemia (7.1 and $7.8 \mathrm{~g} / \mathrm{dL}$ ), while all other patients were discharged with $\mathrm{Hb}>8 \mathrm{~g} / \mathrm{dL}$ (mean $\pm \mathrm{SD}, 11.7 \pm 1.7 \mathrm{~g} / \mathrm{dL}$; range, $7.1-14.7 \mathrm{~g} / \mathrm{dL}$ ).

\section{Outcomes}

Of the 45 Jehovah's Witness patients who had "bloodless" cardiac surgery at Duke University between January 2005 and June 2012, none died before hospital discharge or within the 90-day follow-up. The $\mathrm{Hb}$ at critical time points during the perioperative period is reviewed in Fig. 2. The hospital length of stay averaged 6.2 days and ranged from 3 to 21 days, and ICU length of stay averaged 1.7 days with a range of 1 to 5 days.

\section{DISCUSSION}

Transfusion of allogeneic blood has been found to be associated with increased mortality, ${ }^{8,9}$ increased length of hospital stay, ${ }^{11}$ and end-organ dysfunction. ${ }^{12}$ Cardiac surgery carries a high risk of blood transfusion, consuming $10 \%$ to $15 \%$ of the nation's blood supply. ${ }^{13}$ Witnesses, with their refusal of primary components of blood, bring a unique clinical dilemma to cardiac surgery. Management of these patients must include thorough preoperative planning as well as a multidisciplinary team skilled in blood conservation.

Advances in clinical medicine have led to improved outcomes in Witnesses undergoing cardiac surgery. ${ }^{5-7}$ 


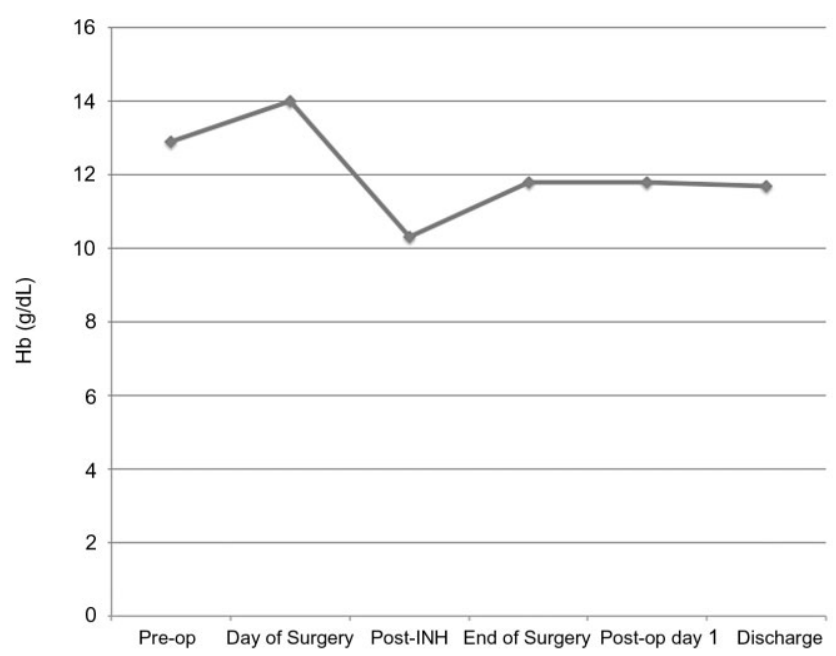

Fig. 2. Mean $\mathrm{Hb}$ values (g/dL) at critical time points in the perioperative period.

Since the introduction of ESAs, preoperative use has been associated with reduced exposure to allogeneic blood products in cardiac surgery; ${ }^{14,15}$ therefore, blood conservation guidelines support the use of ESAs in patients refusing blood transfusion and at risk for postoperative anemia. ${ }^{13}$ Despite these guidelines, concern exists regarding the use of ESAs in cardiac surgery due to the public health advisory released by the US Food and Drug Administration (FDA) warning of an increased risk of thrombosis and death. The study by D'Ambra and colleagues ${ }^{16}$ had more deaths in the ESA group versus the placebo group, but they concluded that the incidence of death was similar to that of CABG in the published literature. Nonetheless, ESAs are not approved by the FDA for treatment of preoperative anemia for cardiac surgery. In blood refusal patients, however, the benefit of optimization of preoperative $\mathrm{Hb}$ before cardiac surgery and the increased risk of mortality from bleeding may outweigh the risks associated with ESAs. Therefore, the patients in this study were counseled of the specific risks associated with ESAs, specifically thrombosis and death, before agreeing to treatment. The data show that the preoperative $\mathrm{Hb}$ was raised by a mean of $1.2 \mathrm{~g} / \mathrm{dL}$ with ESAs, which, with a mean weight in this study population of $88 \mathrm{~kg}$, would correlate to approximately $528 \mathrm{~mL}$ of additional allowable blood loss.

Intraoperatively, INH has been shown to decrease allogeneic blood transfusion ${ }^{17,18}$ and is frequently used in the care of Witnesses. When INH is used intraoperatively, nadir $\mathrm{Hb}$ is typically the $\mathrm{Hb}$ level immediately after autologous harvest, unless significant blood loss occurs during the operative course. A decline of preoperative $\mathrm{Hb}$ to intraoperative nadir $\mathrm{Hb}$ of more than $50 \%$ is associated with adverse outcomes postoperatively and should be avoided. ${ }^{19}$ The results showed a mean difference between day of surgery $\mathrm{Hb}$ and nadir intraoperative $\mathrm{Hb}$ of $26 \%$, well below the recommendation of less than $50 \%$.

Additionally, use of antifibrinolytics during cardiac surgery has been associated with exposure to less blood product transfusion, ${ }^{20}$ and routine use is supported by the blood conservation clinical practice guidelines. ${ }^{13}$ Forty-one of 45 patients in the study received either aprotinin or amicar. Three of the four patients who did not receive antifibrinolytics underwent off-pump CABG. Desmopressin has been found to reduce blood loss only in cardiac surgical procedures with excessive blood loss and is not recommended for routine use in cardiac surgery. ${ }^{13,21}$ Desmopressin enhances PLT function in patients with end-stage renal failure and severe AS and was used for these indications in nine patients. ${ }^{22,23}$ Techniques such as cell salvage and use of RAP during CPB have also shown decreased allogeneic blood transfusion ${ }^{24,25}$ and are supported by the clinical guidelines for blood conservation. ${ }^{13}$ These techniques are employed in all cardiac blood conservation cases, if appropriate for the individual patient and hemodynamically tolerated. Although the patients accepted minor blood fractions, these were rarely given, showing that with proper blood conservation techniques, coagulopathy necessitating transfusion of cryoprecipitate or cryopoor plasma was uncommon.

The ideal CPB time to prevent coagulopathy and severe PLT dysfunction is unknown. Certainly, prolonged runs on $\mathrm{CPB}$ are known to cause coagulopathy. ${ }^{26}$ The mean CPB time was 137 minutes, which could be shortened for less complex surgeries. Additionally, there are little data on the degree of hypothermia that should be used to balance organ protection with coagulopathy. The data showed that patients undergoing valve surgery had a lower nadir temperature on $\mathrm{CPB}$ than patients undergoing only CABG $\left(29.4 \pm 2.1^{\circ} \mathrm{C}\right.$ vs. $\left.31.6 \pm 2.3^{\circ} \mathrm{C}\right)$. More studies are needed to assess the degree of hypothermia that should be targeted in this cohort of patients.

Postoperative care with ESAs was also left to the discretion of the care team, but was used in a small group of patients. The nine patients who received postoperative $\mathrm{EPO}$ had an end-of-surgery $\mathrm{Hb}$ of $10.6 \mathrm{~g} / \mathrm{dL}$ and a discharge $\mathrm{Hb}$ of $9.9 \mathrm{~g} / \mathrm{dL}$. Despite an adequate end-ofsurgery $\mathrm{Hb}$, these patients may have been selected for postoperative ESA therapy due to concerns over chest tube drainage or hemoconcentration due to avoidance of fluid administration.

One limitation to this observational study is the inability to separate the relative contribution of the different techniques employed to overall blood conservation. Since only estimates of patient's blood volume were available, RBC mass was not obtained during the perioperative period. Even RBC mass of the hemodiluted units could not be calculated, given that volume was replaced concurrent with the harvest, and laboratory values were only checked at the beginning and end of INH to minimize blood draws. 
If RBC mass had been obtained before ESA therapy, preoperatively, during INH, and postoperatively, then one could extrapolate the relative contribution of blood salvage versus generation of RBCs.

This is a retrospective descriptive case series and is therefore limited by selection bias. The Witnesses who are selected to undergo cardiac surgery accept INH, cell salvage, and minor blood fractions and do not require circulatory arrest. As such, this cohort of Witnesses may exclude certain higher-risk patients.

Cardiac surgery in Witnesses requires a multidisciplinary team focused on blood conservation. Duke University's CBC and cardiothoracic surgeons work together to select appropriate Jehovah's Witness candidates for cardiothoracic surgery. The CBC has previously calculated surgeons' transfusion rates and identified those with the lowest rates for patient referral. Additionally, perfusionists with experience in INH and CPB in patients refusing transfusion are selected. Witnesses should accept cell saver and INH to maximize the chances of a successful outcome. This institution has not performed any surgeries requiring circulatory arrest, lung transplantation, or implantation of ventricular assist devices in patients refusing blood product transfusion, secondary to either high rates of transfusions or surgeon preference, although a heart transplant was recently performed in a blood refusal patient (not included in this study).

The literature contains multiple studies evaluating different blood conservation therapies and their success in decreasing allogeneic blood transfusion, in addition to studies evaluating outcomes of Witnesses undergoing cardiac surgery, but there are few articles describing a single institution's management of these patients. This article describes the management of Witnesses undergoing cardiac surgery, who with preoperative optimization of anemia, intraoperative techniques including cell salvage, RAP of the CPB circuit, and INH to preserve RBCs and clotting factors, and with perioperative communication and cooperation among the entire surgical team, ultimately had a zero 90-day mortality rate over a 7 -year time period.

\section{ACKNOWLEDGMENT}

The authors thank John Stover for his contribution in preparing Duke University's Center for Blood Conservation protocols that are described in this article.

\section{CONFLICT OF INTEREST}

The authors have disclosed no conflicts of interest.

\section{REFERENCES}

1. International Bible Society. The holy bible: new international version. Vol Acts 15:28-29. Colorado Springs, CO: International Bible Society; 1984.
2. International Bible Society. The holy bible: new international version. Vol Leviticus 17:14. Colorado Springs, CO: International Bible Society; 1984.

3. Watch Tower Bible and Tract Society CBWB, Tract Society of New York. Questions from readers. The Watchtower. Brooklyn, N.Y.; Toronto: Watch Tower Bible and Tract Society of Pennsylvania; Watch Tower Bible and Tract Society. 2004:29-31.

4. Watch Tower Bible and Tract Society CBWB, Tract Society of New York. Questions from readers. The Watchtower. Brooklyn, N.Y.; Toronto: Watch Tower Bible and Tract Society of Pennsylvania; Watch Tower Bible and Tract Society. 2000:30-1.

5. Vaislic CD, Dalibon N, Ponzio O, et al. Outcomes in cardiac surgery in 500 consecutive Jehovah's Witness patients: 21 year experience. J Cardiothorac Surg 2012;7: 95.

6. Pattakos G, Koch CG, Brizzio ME, et al. Outcome of patients who refuse transfusion after cardiac surgery: a natural experiment with severe blood conservation. Arch Intern Med 2012;172:1154-60.

7. Moraca RJ, Wanamaker KM, Bailey SH, et al. Strategies and outcomes of cardiac surgery in Jehovah's Witnesses. J Card Surg 2011;26:135-43.

8. Shaw RE, Johnson CK, Ferrari G, et al. Blood transfusion in cardiac surgery does increase the risk of 5-year mortality: results from a contemporary series of 1714 propensity-matched patients. Transfusion 2014; 54:1106-13.

9. Bhaskar B, Dulhunty J, Mullany DV, et al. Impact of blood product transfusion on short and long-term survival after cardiac surgery: more evidence. Ann Thorac Surg 2012;94: 460-7.

10. LaPar DJ, Crosby IK, Ailawadi G, et al. Blood product conservation is associated with improved outcomes and reduced costs after cardiac surgery. J Thorac Cardiovasc Surg 2013;145:796-803; discussion 803-794.

11. Galas FR, Almeida JP, Fukushima JT, et al. Blood transfusion in cardiac surgery is a risk factor for increased hospital length of stay in adult patients. J Cardiothorac Surg 2013;8:54.

12. Swaminathan M, Phillips-Bute BG, Conlon PJ, et al. The association of lowest hematocrit during cardiopulmonary bypass with acute renal injury after coronary artery bypass surgery. Ann Thorac Surg 2003;76:784-91.

13. Society of Thoracic Surgeons Blood Conservation Guideline Task Force, Ferraris VA, Brown JR, Despotis GJ, et al. 2011 update to the Society of Thoracic Surgeons and the Society of Cardiovascular Anesthesiologists blood conservation clinical practice guidelines. Ann Thorac Surg 2011; 91:944-82.

14. Alghamdi AA, Albanna MJ, Guru V, et al. Does the use of erythropoietin reduce the risk of exposure to allogeneic blood transfusion in cardiac surgery? A systematic review and meta-analysis. J Card Surg 2006;21:320-6. 
15. Weltert L, D'Alessandro S, Nardella S, et al. Preoperative very short-term, high-dose erythropoietin administration diminishes blood transfusion rate in off-pump coronary artery bypass: a randomized blind controlled study. J Thorac Cardiovasc Surg 2010;139:621-6. discussion 626-627.

16. D’Ambra MN, Gray RJ, Hillman R, et al. Effect of recombinant human erythropoietin on transfusion risk in coronary bypass patients. Ann Thorac Surg 1997;64:1686-93.

17. Taketani T, Motomura N, Toyokawa S, et al. Beneficial effect of acute normovolemic hemodilution in cardiovascular surgery. Jpn J Thorac Cardiovasc Surg 2005;53: $16-21$.

18. Casati V, Benussi S, Sandrelli L, et al. Intraoperative moderate acute normovolemic hemodilution associated with a comprehensive blood-sparing protocol in off-pump coronary surgery. Anesth Analg 2004;98:1217-23; table of contents.

19. Karkouti K, Wijeysundera DN, Yau TM, et al. The influence of baseline hemoglobin concentration on tolerance of anemia in cardiac surgery. Transfusion 2008;48: 666-72.

20. Brown JR, Birkmeyer NJ, O'Connor GT. Meta-analysis comparing the effectiveness and adverse outcomes of antifibrinolytic agents in cardiac surgery. Circulation 2007;115:2801-13.

21. Cattaneo M, Harris AS, Stromberg U, et al. The effect of desmopressin on reducing blood loss in cardiac surgery-a meta-analysis of double-blind, placebocontrolled trials. Thromb Haemost 1995;74:1064-70.

22. Zeigler ZR, Megaludis A, Fraley DS. Desmopressin (d-DAVP) effects on platelet rheology and von Willebrand factor activities in uremia. Am J Hematol 1992;39:90-5.

23. Steinlechner B, Zeidler P, Base E, et al. Patients with severe aortic valve stenosis and impaired platelet function benefit from preoperative desmopressin infusion. Ann Thorac Surg 2011;91:1420-6.

24. Wang G, Bainbridge D, Martin J, et al. The efficacy of an intraoperative cell saver during cardiac surgery: a metaanalysis of randomized trials. Anesth Analg 2009;109:32030.

25. Sun P, Ji B, Sun Y, et al. Effects of retrograde autologous priming on blood transfusion and clinical outcomes in adults: a meta-analysis. Perfusion 2013;28:238-43.

26. Wahba A, Rothe G, Lodes H, et al. The influence of the duration of cardiopulmonary bypass on coagulation, fibrinolysis and platelet function. Thorac Cardiovasc Surg 2001;49:153-6. 